Revista Destaques Acadêmicos, Lajeado, v. 10, n. 3, 2018. ISSN 2176-3070

DOI: http://dx.doi.org/10.22410/issn.2176-3070.v10i3a2018.1727

http://www.univates.br/revistas

\title{
FEIRA DE CIÊNCIAS: UMA ESTRATÉGIA PARA PROMOVER A INTERDISCIPLINARIDADE
}

\author{
Nayane De Oliveira Silva ${ }^{1}$, Cristina Guilherme de Almeida ${ }^{2}$, \\ Débora Raquel Sarmento Lima ${ }^{3}$
}

\begin{abstract}
Resumo: As feiras de ciências são uma importante ferramenta de integração da escola com a comunidade, pois elas dão oportunidade para os alunos demonstrarem, por meio de projetos próprios, seu conhecimento científico, sua lógica e sua criatividade. O presente trabalho consistiu em avaliar qualitativamente a aceitação dos professores quanto à realização das feiras de ciências como uma estratégia para promover a interdisciplinaridade nas escolas. Para isso, foi organizada uma feira de ciências em um colégio de ensino médio do município de Campo Mourão, Paraná, onde, após a realização da mesma, os professores participantes responderam a um questionário. Os professores expressaram conhecimento considerável sobre esse tipo de evento e sobre a interdisciplinaridade e ressaltaram a sua importância para as disciplinas em que lecionam. Diante dos resultados, ficou evidente que as feiras de ciências constituem uma importante ferramenta para promover a interdisciplinaridade nas escolas, além de integrar as disciplinas, os conteúdos e toda a comunidade escolar, proporcionando aos alunos independência, oportunidade de crescimento pessoal e fuga da rotina escolar, tornando os alunos atuantes no processo de ensino e aprendizagem.
\end{abstract}

Palavras-chave: Aprendizagem. Contextualização. Ensino. Integração.

\section{INTRODUÇÃO}

Entre os principais objetivos do professor ao ensinar ciências, está a busca em desenvolver no aluno uma conduta reflexiva, crítica, questionadora e investigadora, possibilitando ao mesmo uma visão efetiva das teorias que explicam os fenômenos da natureza (MARTINS; USTRA, 2016). Alcançar esses

1 Acadêmica do curso de Ciências biológicas no Centro Universitário Integrado.

2 Graduada em Ciências Biológicas pela UEPG. Doutora em Ciências Ambientais pela UEM. Docente do Centro Universitário Integrado.

3 Graduada em Ciências Biológicas pela Faculdade Integrado de Campo Mourão. Mestre em Ensino de Ciências e Educação Matemática pela UEL. Docente do Centro Universitário Integrado. 
objetivos é o principal desafio do professor, que encontra muitos obstáculos durante o processo de ensino. Entre esses empecilhos, Oaigen, Bernard e Souza (2013) ressaltam que frequentemente se presencia nas escolas a repetição de temas especificados por um currículo, geralmente descontextualizado, muitas vezes inconsistente, que os autores compararam a "Pinceladas num quadro sem forma, sem perspectiva", incapaz de despertar no aluno o interesse pela pesquisa e oferecer o espaço que o mesmo necessita para desenvolver seu próprio jeito de pensar e suas habilidades inatas.

A construção curricular e a opção pela interdisciplinaridade traz consigo uma reflexão, um contraponto sobre currículos tradicionais com uma visão disciplinar e o conhecimento do senso comum, entretanto o senso comum quando interpenetrado pelo conhecimento científico que pode conduzir a uma ruptura epistemológica, uma nova racionalidade (FAZENDA, 2005).

O que com isso queremos dizer é que o pensar interdisciplinar parte do princípio de que nenhuma forma de conhecimento é em si mesma racional. Tenta, pois, o diálogo com outras formas de conhecimento, deixando-se interpenetrar por elas. Assim, por exemplo, aceita o conhecimento do senso comum como válido, pois é através do cotidiano que damos sentido às nossas vidas. Ampliado através do diálogo com o conhecimento científico, tende a uma dimensão utópica e libertadora, pois permite enriquecer nossa relação com o outro e com o mundo (FAZENDA, 2005, p. 17).

No projeto interdisciplinar causa e intenção precisam coincidir, é preciso envolvimento das pessoas e das instituições para que se exerça a interdisciplinaridade e se busque uma aprendizagem significativa para todos os sujeitos.

As metodologias empregadas no ensino passam por um contínuo processo de aprimoramento e sofrem constantes mudanças, entre essas mudanças a contextualização e a interdisciplinaridade são as mais pautadas quando se fala de construir uma aprendizagem significativa (PONTIN et al., 2015). Demo (1994) acredita que prevalece em nós o hábito de imitador, que somente copia, reproduz e faz prova, quando deveríamos construir um método próprio, ao invés de esperarmos receitas prontas. Para que se efetive uma aprendizagem significativa e um olhar crítico é essencial que se estimule o desenvolvimento do pensar, é fundamental que a escola contextualize o ensino à realidade da comunidade em que está inserida (OAIGEN; BERNARD; SOUZA, 2013).

Nesse sentido, eventos como as feiras de ciências figuram como uma importante ferramenta de integração da escola com a comunidade, pois as mesmas dão oportunidade para os alunos demonstrarem, por meio de projetos próprios, seus conhecimentos científicos, sua lógica e sua criatividade (MANCUSO, 2000). 
Assim, o objetivo do presente trabalho foi avaliar a aceitação dos professores de uma escola de ensino médio no município de Campo Mourão, Paraná, em relação à feira de ciências como uma estratégia para promover a interdisciplinaridade no ambiente escolar.

\section{METODOLOGIA}

A pesquisa realizada foi de abordagem qualitativa, que de modo geral não busca listar ou mensurar os eventos estudados, nem emprega instrumentos estatísticos para analisar os dados obtidos. Ela se origina de indagações amplas, que vão se especificando conforme o estudo se desenvolve (GODOY, 1995). Bento (2012) ressalta que a investigação qualitativa foca um modelo fenomenológico no qual a realidade é enraizada nas percepções dos sujeitos. Para o autor, o objetivo dela é compreender e encontrar significados através de narrativas verbais e de observações em vez de através de números, o contrário da pesquisa de abordagem quantitativa, na qual se busca expressar os fatos numericamente.

A coleta de dados foi realizada por meio de um questionário contendo oito perguntas, disponibilizado para os professores participantes. Gil (1999) define o questionário como uma técnica investigativa constituída de um número relativamente elevado de questões redigidas e apresentada às pessoas com o intuito de observar opiniões, crenças, sentimentos, expectativas, etc. $\mathrm{O}$ questionário usado na pesquisa consistiu nas seguintes perguntas: 1) Qual a disciplina que você leciona? Qual sua formação acadêmica? 2) Em que séries leciona? 3) Como sua disciplina contribuiria com uma feira de ciências? 4) Como a feira de ciências contribuiria para a sua prática pedagógica? 5) O que é interdisciplinaridade para você? 6) Já aplicou algum projeto interdisciplinar? Quais foram os resultados? 7) Você acredita que a feira de ciências é uma forma eficaz de promover a interdisciplinaridade? 8) Você trabalha interdisciplinaridade em suas aulas?

A análise de conteúdo foi o procedimento de pesquisa escolhido como metodologia por se dedicar às comunicações. Bardin (2001) afirma que as comunicações possuem um vasto território de manifestação, tanto de ordem oral quanto escrita, logo, se aplica ao trabalho de análise dos questionários. $\mathrm{O}$ autor organiza a análise em três polos cronológicos:

1. A pré-análise;

2. A exploração do material;

3. O tratamento dos resultados, a inferência e a interpretação.

A pré-análise é a organização inicial e consistem na escolha dos documentos para análise, a formulação de hipóteses e objetivos e a elaboração de indicadores que fundamentem a interpretação final (BARDIN, 2001). A fase de exploração do material consistiu basicamente em codificação e enumeração. O código estabelecido para representar o professor é (P), seguido por um 
número indicativo (como são cinco professores participantes, o código vai do P1 ao P5).

A pesquisa contou com a participação de cinco professores presentes no dia da realização da feira de ciências no Colégio Estadual Novo Horizonte, Campo Mourão, Paraná, escola escolhida para a realização da pesquisa.

Cumpridas as etapas 1 e 2 estabelecidas por Bardin (2001), procedeu-se à fase 3, na qual se constituíram as interpretações e construção das análises, sempre buscando apoio na literatura específica para a discussão dos resultados.

\section{RESULTADOS E DISCUSSÃO}

Após a realização da feira de ciências, foi entregue aos professores presentes um questionário. Estavam presentes no dia da feira, realizada em uma sexta-feira no período noturno, cinco professores que seguem relacionados no quadro abaixo (Quadro 1), juntamente com as disciplinas que lecionam e respectiva formação acadêmica.

Quadro 1 - Relação dos professores que participaram da feira de ciências, disciplina em que lecionam e sua formação acadêmica.

\begin{tabular}{|l|c|c|}
\hline Professor & Disciplina em que leciona & Formação acadêmica \\
\hline P1 & Geografia & Geografia. \\
\hline P2 & Inglês & Letras - Português/Inglês \\
\hline P3 & Matemática & Matemática \\
\hline P4 & Filosofia & Artes, Filosofia e Pedagogia \\
\hline P5 & Inglês & Letras - Português/Inglês \\
\hline
\end{tabular}

Fonte: Dados da pesquisa.

Nota-se em muitas escolas do Brasil um grave problema relacionado com a tendência cada vez mais crescente de professores não habilitados, profissionais de outras áreas ou estudantes sem a graduação na área específica para ministrar a disciplina que lecionam. Segundo reportagem recente publicada no Jornal da USP (2017) dos 494 mil docentes que trabalham no ensino médio, 228 mil (46,3\%) atuam em pelo menos uma disciplina para a qual não têm formação, sendo que o número de professores com formação adequada em todas as aulas dadas representa 53,7\% do total. Esse problema já foi evidenciado anteriormente pela pesquisadora Patinha (1999), ela investigou o número de professores que atuavam na rede pública do Estado de São Paulo, suas respectivas formações e as disciplinas em que lecionavam, constatando um número elevado de professores lecionando em áreas em que não eram habilitados (PATINHA,1999; PASSOS e OLIVEIRA, 2008). 
No entanto, analisando as respostas dos professores presentes na feira, pode-se constatar que todos eles têm formação acadêmica na área em que lecionam, sendo que um deles, $\mathrm{P} 4$, além de ser graduado na disciplina que leciona, também possui graduação em outras duas áreas, Artes e Pedagogia. Isso certamente contribui para que a escola em que foi realizada a pesquisa oferte um ensino de maior qualidade para os alunos, com professores mais qualificados e preparados para lidar com os desafios presentes nas salas de aula.

Todos os professores que participaram da pesquisa lecionam nos três anos do Ensino Médio, sendo que dois deles, P4 e P5, lecionam também do sexto ao nono ano, e um deles, P3, leciona no sexto e sétimo ano do Ensino Fundamental - Anos Finais.

Quando questionados sobre de que maneira as disciplinas de cada professor poderiam contribuir com uma feira de ciências, as respostas foram bastante diversificadas (Quadro 2), variando de um professor para o outro sendo que um deles, o P5, não respondeu. Os professores P1 e P3 apresentam uma linha de raciocínio semelhante, pois concordam que trabalhar conteúdos práticos e do cotidiano do aluno é muito importante no desenvolvimento dessas feiras e certamente contribuem para o número crescente de projetos que adquirem cada vez mais caráter interdisciplinar, que em grande parte são motivados por problemas e com soluções existentes na própria comunidade, mostrando uma contextualização dos conhecimentos (MEC, 2006). Para Oaigen (1996), é inconcebível pensar em uma educação que se afaste do contexto social, como frequentemente tem se presenciado. $\mathrm{O}$ autor acredita que é através da educação científica que se pode preparar o indivíduo para viver em sociedade, possibilitando ao mesmo as ferramentas das quais ele carece para solucionar os problemas e dificuldades do dia a dia.

Muitas vezes, acredita-se que em uma feira de ciências só poderão contribuir disciplinas tidas como propriamente "científicas", como biologia, física, química, etc. P2, que leciona inglês, encontrou uma saída para desmistificar essa crença, pois ao responder de que forma sua disciplina pode contribuir com uma feira de ciências ele apresentou a ideia de trabalhar a leitura de textos e artigos científicos em outros idiomas, no caso o inglês, que estejam ligados com as outras disciplinas. Esses artigos são fundamentais para a construção dos projetos que compõem a feira. P4, que leciona filosofia, também apresenta uma ideia, ele fala da possibilidade de estar colocando em pauta projetos relacionados à tecnologia e usando a filosofia para trabalhar os debates relacionados às vantagens e desvantagens ligadas ao desenvolvimento tecnológico.

De uma forma ou de outra, todas as disciplinas podem contribuir diretamente ou indiretamente para a construção de uma feira de ciências, nessa hora vale a criatividade do professor, em buscar maneiras de estar de alguma forma inserindo sua disciplina no contexto interdisciplinar. 
Quadro 2 - Relação dos professores que participaram da pesquisa e como cada um acredita que a disciplina que leciona pode contribuir com uma feira de ciências.

\begin{tabular}{|c|l|}
\hline Professor & \multicolumn{1}{|c|}{ Como sua disciplina contribui com uma feira de ciências? } \\
\hline P1 & $\begin{array}{l}\text { Trabalho conteúdos práticos como: pedologia, clima, hidrografia, relevo } \\
\text { e outro conteúdo de forma prazerosa para os alunos e também para o } \\
\text { corpo docente. }\end{array}$ \\
\hline P2 & $\begin{array}{l}\text { Apresentando estratégias para um estudo em conjunto com outras } \\
\text { disciplinas. A LEM (Língua Estrangeira Moderna) dialoga com as } \\
\text { disciplinas de Ciências da Natureza na medida em que os textos } \\
\text { estudados nas aulas de inglês podem contribuir para um entendimento } \\
\text { maior na área de ciências aplicadas. }\end{array}$ \\
\hline P3 & $\begin{array}{l}\text { A matemática é uma ciência que está presente na nossa vida diária, } \\
\text { sendo assim contribui de diversas formas como: gastos com luz e água, } \\
\text { interpretação de embalagens, enfim contribui muito. }\end{array}$ \\
\hline P4 & Experiência tecnológica, as vantagens e desvantagens da ciência. \\
\hline P5 & Não respondeu. \\
\hline
\end{tabular}

Fonte: Dados da pesquisa.

Para Oaigen (1996), são situações totalmente opostas o aprender meramente pela imitação e pela reprodução de se aprender pelo ato construtivo e problematizador, o autor afirma que só se aprende de verdade construindo, não apenas escutando aula e anotando informações. Nesse sentido, as feiras de ciências podem constituir uma ferramenta importante para melhorar a aprendizagem dos alunos quando incorporadas ao contexto escolar, e foi consenso entre os professores que participaram da pesquisa que elas contribuem de alguma forma para suas práticas pedagógicas, exceto o P5 que não respondeu a questão. O professor P2 ressaltou em sua resposta a importância das feiras, ao passo que, segundo suas próprias palavras, oferecem "motivação aos estudantes, espaço criativo para a troca de ideias, além de ser uma forma divertida de instrumentalizá-los com o conhecimento". O professor P4, que leciona filosofia, disciplina que pode ser considerada difícil de integrar à uma feira, colocou o debate e a reflexão sobre a ética e a ciência com uma forma de ter a feira de ciências utilizada durante suas aulas. Os professores P1 e P2 tiveram opiniões semelhantes, ambos concordam que ela é extremamente enriquecedora; nas palavras do professor P1, elas permitem "formas novas de passar conteúdos, interdisciplinares ou não, dentro dos conteúdos propostos", o mesmo enfatiza ainda a necessidade das feiras serem mais e melhor exploradas, pois constituem uma ferramenta importante no constante processo de aprendizagem. 
As feiras também oportunizam ao professor avaliar mudanças no comportamento de seus alunos, seu envolvimento com a pesquisa, o aprimoramento cognitivo nas áreas da ciência e/ou tecnologia, bem como o desenvolvimento de sua capacidade de raciocínio e habilidades criativas (OAIGEN; BERNARD; SOUZA, 2013). Os trabalhos elaborados e apresentados em uma feira ilustram uma metodologia ativa em sala de aula e apresentam conforme ressaltam os autores Oaigen, Bernard e Souza (2013): Uma concepção interdisciplinar da pesquisa científica, que vai desde as investigações empíricas tradicionais até investigações de cunho materialismo dialéticas.

Diversas vezes, ao longo deste trabalho, foi citado o termo "interdisciplinar" ou "interdisciplinaridade", que inclusive consta no título do trabalho. Sua importância para este trabalho é indiscutível, pois para Leis (2005) a interdisciplinaridade é tida como uma condição fundamental do ensino e da pesquisa na sociedade contemporânea.

De acordo com Hartmann e Zimmermann (2009), o parecer mais comum encontrado na literatura e entre professores é de que a interdisciplinaridade é composta de uma associação dos conteúdos. Partindo dessa ideia, indagouse o que cada um dos professores entendia por "interdisciplinaridade". As respostas de todos são similares e coincidem com a ideia apresentada por Hartmann e Zimmermann (2009) e por outros pesquisadores da área. Em síntese, para os professores a interdisciplinaridade consiste em se trabalhar de forma integrada um mesmo conteúdo em diversas disciplinas, conforme as propriedades de cada uma. O professor P2 exemplifica o termo dizendo que a interdisciplinaridade acontece quando "se tem um tema como 'fio condutor' e as disciplinas todas contribuem para que o aluno/estudante seja instrumentalizado nessa temática. Em outras palavras, quando se dá as mãos em um objetivo comum". O professor P2 acredita que a interdisciplinaridade consiste em interpor as disciplinas de forma que os conteúdos não fiquem estanques ou como "Pinceladas num quadro sem forma, sem perspectiva", como afirmam os pesquisadores Oaigen, Bernard e Souza e (2013), os quais acreditam que a escola muitas vezes apresenta um currículo descontextualizado que consiste na repetição de temas incoerentes.

Pombo (2003) em seu trabalho afirma que falar sobre interdisciplinaridade nos dias de hoje é uma tarefa difícil, para não dizer quase impossível, já que nem todos sabem o que é interdisciplinaridade, pois não existe nenhuma estabilidade sobre esse conceito e até mesmo entre os especialistas da área existem as mais díspares definições sobre o que é interdisciplinaridade. Além disso, a palavra vem sendo banalizada, graças talvez a sua vasta utilização que pode ser aplicada a amplos contextos.

Japiassu (1976) em seu livro "Interdisciplinaridade e Patologia do Saber" reconhece que ainda não há um sentido epistemológico único para o termo interdisciplinaridade, mas entende que a mesma se trata de um processo onde há interatividade mútua, onde uma disciplina influencia e se deixa influenciar 
pelas outras, e acredita que através dela pode se estabelecer novamente a unidade do conhecimento. Desde Aristóteles até Auguste Comte, acreditava-se ser possível desenvolver uma cultura realmente universal e educar as pessoas para que elas pudessem circular com tranquilidade entre as diferentes áreas, sejam elas artes, letras ou ciências (SCHWARTZMAN,1992). Na idade moderna esse saber comum atravessou um processo de fragmentação culminando nas centenas de especializações que encontramos hoje e que o pesquisador Japissu (1976) denomina como "patologias do saber", o mesmo acredita que a interdisciplinaridade é fundamental para vencer essa fragmentação das disciplinas e proporcionar ao homem o conhecimento em totalidade e não em parcelas, como frequentemente se presencia.

Para Leis (2005), um dos obstáculos para se entender o sentido da atividade interdisciplinar reside justamente no fato dos pesquisadores se envolverem em debates intermináveis em busca de tentar homogeneizar o seu conceito, sendo que isso atenta diretamente contra a própria prática da interdisciplinaridade, contrária a qualquer enquadramento conceitual. Apesar de não haver um consenso sobre o conceito, a concepção dos autores deste presente artigo é a que propõe Pombo (1993) que entende a interdisciplinaridade como:

[...] qualquer forma de combinação entre duas ou mais disciplinas com vista à compreensão de um objecto a partir da confluência de pontos de vista diferentes e tendo como objectivo final a elaboração de uma síntese relativamente ao objecto comum. A interdisciplinaridade implica, portanto, alguma reorganização do processo de ensino/aprendizagem e supõe um trabalho continuado de cooperação dos professores envolvidos (POMBO, 1993, p. 13).

Depois de analisar o conhecimento que os professores tinham sobre a interdisciplinaridade, questionou-se se algum deles já havia aplicado algum projeto interdisciplinar, em caso de resposta positiva, quais os resultados foram obtidos. P5 e P4 não se recordam de ter aplicado nenhum projeto interdisciplinar ao longo da carreira. Os demais professores já aplicaram esse tipo de projeto e em consenso ressaltam que os resultados foram positivos. P1 afirma ainda que a prática contribuiu para despertar o interesse dos alunos, melhorando assim, o aprendizado.

P2, além de lecionar no colégio onde foi realizada a pesquisa, trabalha também no Colégio SESI de Campo Mourão, que faz parte de uma rede de ensino médio particular criado no Paraná em 2005 por iniciativa do Serviço Social da Indústria (SESI). Esse colégio tem como principal característica apresentar uma metodologia diferenciada que coincide, em muitos aspectos, com a ideia de interdisciplinaridade. A metodologia é fundamentada em um conceito de educação participativa apoiada no diálogo entre saberes e interação entre pares para solução de desafios que despertam o prazer em aprender 
(COLÉGIO SESI, 2011). O professor P2 afirma que obtém excelentes resultados com essa metodologia. Cabe aqui, complementar com a ideia dos pesquisadores Vincenzzi, Alves e Rhoden (2010), que afirmam que se faz necessário valorizar o processo de aprendizagem de forma integrada entre as disciplinas e não apenas o conhecimento difundido de maneira precisa nas diferentes áreas de ensino.

Segundo Oaigen, Bernard e Souza (2013), as feiras de ciências podem contribuir para despertar no aluno o interesse em conhecer melhor os diversos aspectos de sua realidade (social, econômica, política, entre outros) por meio de tarefas que o estimule a observar e investigar de forma científica o mundo que está a sua volta, fazendo com que o mesmo aprenda desde cedo a planejar e executar experiências e projetos, adquirindo assim, confiança e uma visão crítica e criativa frente à resolução de problemas. O planejamento e execução de uma feira de ciências corroboram com o que é proposto quando se fala de interdisciplinaridade, pois busca contextualizar os conhecimentos científicos com o cotidiano do aluno e da comunidade em que o mesmo está inserido, sem deixar de lado as particularidades de cada disciplina (CARMINATTI; BEDIN, 2013).

Quando questionados se a feira de ciências é uma forma eficaz para promover a interdisciplinaridade, a resposta foi unânime, todos os professores responderam que sim. P2 afirma acreditar que "Uma feira de ciências é uma forma perfeita de envolver as áreas de conhecimento, além de envolver os alunos", P5 segue uma linha de raciocínio semelhante afirmando que permite que um determinado conteúdo seja visto através de vários ângulos, que é o cerne da interdisciplinaridade que consiste em buscar explicação para os fenômenos abrangendo as diversas áreas do conhecimento. P1 afirma que é uma das formas mais positivas e com excelentes resultados, como pode ser comprovado durante a realização da feira que contou com a expressiva participação dos alunos nos projetos interdisciplinares que foram desenvolvidos na escola.

Visto que na feira de ciências apresentada no colégio e na coleta de dados por meio de questionário, os professores expressaram um conhecimento significativo sobre o tema, ressaltaram a importância da interdisciplinaridade para a disciplina em que lecionam, para a feira de ciências e para o aprendizado de seus alunos, questionou-se então se eles trabalhavam a interdisciplinaridade em suas aulas, e todos afirmaram que sim, exceto P5. P4 afirma trabalhar interdisciplinaridade em conteúdos como ética e ciência, direitos humanos, filosofia e política, fazendo reflexões desses temas envolvendo as outras disciplinas. P2 ressalta que suas aulas têm como objetivo "desenvolver habilidades de leitura de mundo e compreensão, a partir de uma língua e cultura estrangeiras", seguindo um rumo um pouco diferente dos demais professores que falaram apenas da interdisciplinaridade voltada para trabalhar um conteúdo em diversas disciplinas, ele fala em trabalhar em suas aulas a 
interdisciplinaridade voltada também para uma melhor compreensão do mundo, e não apenas de conteúdos.

Levando em conta que a educação é um processo que se modifica continuamente, é inconcebível que ela seja vista unicamente como a transmissão de um saber pronto e acabado, é imprescindível que ela se construa em um processo dinâmico partindo de situações do cotidiano do aluno, valorizando a teoria e a prática dentro de uma concepção crítica e criativa. Para que isso aconteça, a sala de aula deve ser transformada em um local de trabalho conjunto onde o professor não seja o único privilegiado, mas que o aluno possa ter liberdade e autonomia (OAIGEN; BERNARD; SOUZA, 2013).

Durante a realização da feira de ciências foi nítido o entusiasmo dos alunos em conhecer os projetos que estavam sendo apresentados, eles participaram das demonstrações, responderam as perguntas que eram levantadas e também expressaram suas dúvidas, curiosidades por vezes coibidas dentro do ensino formal e tradicional. Durante a feira de ciências fica evidente que todos saem ganhando, seja quem apresenta os projetos, que ao ensinar mobiliza saberes ligados ao conhecimento e à docência, ou o espectador que acessa o conhecimento de uma forma dinâmica, sendo integrantes do processo e não meros receptores passivos de informação.

\section{CONCLUSÃO}

Os resultados obtidos evidenciaram que foi consenso entre os professores participantes desta pesquisa que as feiras de ciências constituem uma importante ferramenta para promover a interdisciplinaridade nas escolas, isto porque, além de estarem integrando as disciplinas, os conteúdos e toda a comunidade escolar, oferece aos alunos independência, oportunidade de crescimento pessoal e fuga da rotina escolar, tornando os alunos atuantes no processo de ensino e aprendizagem.

Vista a importância desses eventos, é necessário o incentivo dos professores, das escolas e do Governo para que eles sejam melhor aproveitados, incentivando os alunos a desenvolver projetos, pensar em soluções para problemas reais da comunidade e divulgar a ciência; todas essas ações visam o desenvolvimento de uma educação significativa e a valorização da ciência por todos os agentes da educação básica.

A realização das feiras de ciências nas escolas carece também de um novo caráter. Frequentemente, presencia-se a repetição de projetos que consistem em uma receita pronta, os quais antes mesmo de serem realizados, todos já sabem os resultados que serão obtidos. É imprescindível encorajar os alunos a buscarem projetos inovadores, observar os problemas que estão a sua volta e procurar soluções para resolvê-los. 


\section{REFERÊNCIAS}

BARDIN, Laurence. Análise de conteúdo. São Paulo: Edições 70, 2001.

BENTO, Antônio V. Investigação quantitativa e qualitativa: Dicotomia ou complementaridade?. Revista JA (Associação Académica da Universidade da Madeira), nº 64, ano VII, p. 40-43, 2012.

CARMINATTI, B.; BEDIN, E. A feira de ciências como ferramenta de aprendizagem: uma experiência de contextualização e interdisciplinaridade no Ensino de Ciências.

Encontro de Debates sobre o Ensino de Química, v. 1, n. 01, 2013.

COLÉGIO SESI. Ensino médio. Proposta Pedagógica. Curitiba: SESI-PR, 2011.

DEMO, Pedro. A Nova LDB: Ranços e Avanços. 6. ed. São Paulo: Papirus, 1994.

FAZENDA, Ivani C. A. Interdisciplinaridade: definição, projeto, pesquisa. In: (Org.). Práticas interdisciplinares na escola. Cortez Editora, 2005. p. 15 - 18.

GIL, Antônio Carlos. Métodos e técnicas de pesquisa social. 5. ed. São Paulo: Atlas, 1999.

GODOY, Arilda Schimidt. Introdução à pesquisa qualitativa e suas possibilidades. Revista de administração de empresas, v. 35, n. 2, p. 57-63, 1995.

HARTMANN, Ângela Maria; ZIMMERMANN, Erica. Feira de Ciências: a interdisciplinaridade e a contextualização em produções de estudantes de ensino médio. In: VII ENPEC - Encontro Nacional de Pesquisa em educação e Ciências, Florianópolis - SC, 2009. Disponível em: <http:/ / posgrad.fae.ufmg.br/posgrad/ viienpec/pdfs/178.pdf>. Acesso em: 10 de set. de 2016.

JAPIASSU, Hilton. Interdisciplinaridade e Patologia do Saber. Rio de Janeiro: Imago Editora, 1976.

JORNAL DA USP. Professor sem formação específica, problema a ser solucionado. 2017. Disponível em: <https://jornal.usp.br/?p=67085>. Acesso em 28 de out. 2018.

LEIS, H. R. Sobre o conceito de interdisciplinaridade. Cadernos de pesquisa interdisciplinar em ciências humanas, v. 6, n. 73, p. 2-23, 2005.

MARTINS, Nicolas Fernandes; USTRA, Sandro Rogério Vargas. Contextualização de uma feira de ciências e suas contribuições para a educação científica. Disponível em: <revistas.jatai.ufg.br/index.php/acp/article/download/1407/808>. Acesso em: 10 de set. de 2016.

MINISTÉRIO DA EDUCAÇÃO (MEC). Secretaria de Educação Básica. Programa Nacional de Apoio às Feiras de Ciências da Educação Básica: Fenaceb. Brasília: MEC/SEB, 2006. 
OAIGEN, E. R.; BERNARD, T.; SOUZA, C. A. Avaliação do evento feiras de ciências: aspectos científicos, educacionais, socioculturais e ambientais. Revista Destaques Acadêmicos, Edição especial, 2013.

OAIGEN. E. R. Atividades extraclasse e não-formais, uma política para a formação do pesquisador. Memória científica 4; grifos. Chapecó: Ed. Universitária UNOESC, 1996. $161 \mathrm{p}$.

PASSOS, L. F.; OLIVEIRA, N. S. C. Professores não habilitados e os programas especiais de formação de professores: a tábua de salvação ou a descaracterização. Rev. Diálogo Educação, Curitiba, v. 8, n. 23, p. 105-120, 2008.

PATINHA, V. A. Professor não-habilitado: um sinal da crise na educação. 1999. 212 f. 1999. Tese de Doutorado. Tese (Doutorado em Educação: História e Filosofia da Educação) - Pontifícia Universidade Católica de São Paulo, São Paulo.

POMBO, Olga. O conceito de interdisciplinaridade e conceitos afins. IN: POMBO, Olga; GUIMARÃES, Henrique M.; LEVY, Teresa. A interdisciplinaridade: reflexão e experiência. Lisboa: Texto Editora, 1993.

POMBO, O. Epistemologia da interdisciplinaridade. In: SEMINÁRIO INTERNACIONAL INTERDISCIPLINARIDADE, HUMANISMO, UNIVERSIDADE. 2003. Anais...Porto: Universidade do Porto, 2003. p. 1-18. (Cátedra Humanismo Latino). Disponível em: <http://www.humanismolatino.online.pt/v1/pdf/C002_11. pdf>. Acesso em: 20 maio 2011.

PONTIN, G. I.; PIMENTA, L. O.; SILVA, M. F.; ARAÚJO PEREIRA, V. R.; SOUZA, L. M; VECCHINI CATANI, K. C. As dificuldades da interdisciplinaridade e contextualização em Uma feira de ciências. I Seminário de Iniciação à Docência.

Anais... Barretos. v. 1, n.1, 2015.

SCHWARTZMAN, Simon. O sentido da interdisciplinaridade. Novos estudos CEBRAP, v. 32, p. 191-8, 1992.

VINCENZZI, E. A.; ALVES, D. R. S.; RHODEN, S. A. Avaliando a Metodologia SESI: concepções dos alunos, formandos de 2009 Toledo/PR, sobre trabalho em equipe, interdisciplinaridade e construção do conhecimento. In: Sinect - II Simpósio Nacional de Ensino de Ciências e Tecnologia, 2010, Ponta Grossa/PR. II SINECT, 2010. 